\title{
KAJIAN POTENSI DAN STRATEGI PENGEMBANGAN EKOWISATA DI HUTAN MERANTI KABUPATEN KOTABARU-KALIMANTAN SELATAN
}

\author{
Ifnu Soleh Al Amin', Tatag Muttaqin', Erni Mukti \\ ${ }^{1}$ Jurusan Kehutanan, Fakultas Pertanian Peternakan, Universitas Muhammadiyah Malang \\ Email : febriarif14@gmail.com
}

\section{RANGKUMAN}

Penelitian ini bertujuan untuk mengkaji potensi obyek wisata alam sebagai daya tarik wisata dan strategi pengembangan ekowisata di hutan meranti agar memberi pengaruh terhadap perkembangan ekologi, ekomoni, dan sosial masyarakat pada pengelolaan ekowisata di hutan meranti. Penelitian ini dilakukan di Hutan Meranti Kotabaru, Kalimantan Selatan pada bulan Januari-Februari 2017, Metode dasar yang digunakan dalam penelitian ini adalah menilai potensi atraksi, kondisi kawasan, kondisi masyarakat dan wisatawan serta pengelolaan kawasan. Analisis data dilakukan dengan metode deskiptif.

Hasil penelitian menunjukkan bahwa Kawasan Ekowisata Hutan Meranti memiliki potensi yang masih dapat dikembangkan, Seluruh masyarakat sangat mendukung adanya pemberdayaan masyarakat karena dapat meningkatkan taraf hidup masyarakat sekitar. Hasil dari Analisis SWOT dapat dijadikan strategi pengembangan Ekowisata Hutan Meranti, yaitu; a) Penguatan konsep ecotourism bagi Ekowisata Hutan Meranti, b) Penataan kembali ruang untuk kegiatan ekowisata, c) Mendorong linkage dengan travel unit (agen perjalanan), d) Mendorong partisipasi dan pemberdayaan masyarakat Wisata, e) Mendorong unit-unit usaha yang strategis, f) Melakukan promosi yang gencar.

Kata kunci: Analisi SWOT, Ekowisata, Hutan Meranti, Strategi Pengembangan

\section{ABSTRAK}

This study aims to examine the potential of natural attractions as a tourist attraction and ecotourism development strategy in meranti forest in order to give influence to the ecological, eco and social development of the community on ecotourism management in meranti forest. This research was conducted in Meranti Kotabaru Forest, South Kalimantan in January-February 2017. The basic method used in this research is to assess the potential of attraction, the condition of the area, the condition of the people and the tourists and the management of the area. Data analysis was done by descriptive method.

The results showed that the Ecotourism Area of Meranti Forest has potential that can still be developed, All people strongly support the empowerment of society because it can improve the living standard of the surrounding community. Results of SWOT Analysis can be used as a development strategy of Meranti Forest Ecotourism, namely; a) Strengthening ecotourism concept for Ecotourism of Meranti Forest, b) Reorganization of space for ecotourism activities, c) Encouraging linkage with travel unit, d) Encouraging participation and empowerment of tourism community, e) Encouraging strategic business units, f) Conduct a vigorous promotion.

Keywords: SWOT Analysis, Ecotourism, Meranti Forest, Development Strategy

\section{PENDAHULUAN}

Ekowisata sering dikatakan sebagai green industry yang menciptakan pariwisata berkualitas, memungkinkan wisatawan dalam kelompok kecil dan dapat mempertahankan kualitas objek dan daya tarik alam berupa hutan, sungai, danau, pantai serta meningkatkan pendapatan dan kesejahtraan masyarakat lokal.

Ekowisata Hutan Meranti merupakan suatu upaya pemanfaatan sumberdaya lokal yang optimal dengan mengembangkan pariwisata dengan konsep ekowisata. Wisata yang dilakukan dalam konteks ini memiliki bagian yang tidak terpisahkan dengan upayaupaya konservasi, pemberdayaan ekonomi lokal dan saling menghargai perbedaan kultur atau budaya.

Karakter kawasan Hutan sesuai dengan karakter kawasan yang dapat dikembangkan sebagai kawasan ekowisata, yaitu kondisinya yang masih alami dan masih ber-cirikan 
pedesaan, serta memiliki banyak potensi wisata yang dapat dikembangkan. Akan tetapi, kawasan tersebut masih memiliki banyak permasalahan, baik dari aspek lingkungan, aspek pengelolaan, hingga aspek sumberdaya manusia, sehingga aktivitas wisata di kawasan Hutan meranti sebagai salah satu kawasan pelestarian alam yang memiliki potensi ODTWA membutuhkan perencanaan yang dapat memberikan gambaran bagaimana pariwisata dan hal-hal yang berkaitan dengan wisata untuk pengelolaannya ke depan.

Tujuan penelitian untuk mengetahui potensi dan strategi pengembangan Ekowisata di Hutan Meranti di Kabupaten Kotabaru: 1) Mengkaji kondisi kawasan hutan meranti yang dikenal masyarakat sebagai kawasan wisata. 2) Mengkaji potensi ekowisata untuk digunakan sebagai dasar evaluasi fungsi dan status kawasan serta sebagai dasar untuk pengembangan ekowisata di kawasan hutan meranti.. 3) Mengkaji strategi yang tepat untuk pengembangan ekowisata di kawasan hutan meranti berdasarkan persepsi wisatawan dan stakeholder.

\section{METODE PENELITIAN}

\section{Waktu dan Tempat Penelitian}

Penelitian ini dilakukan pada bulan Januari 2017 hingga bulan Februari 2017 yang berada di Desa Sebelimbingan Kabupaten Kotabaru Kalimantan Selatan

\section{Alat dan Bahan}

Alat dan bahan yang digunakan untuk mendukung keberhasilan penelitian ini yaitu alat tulis, kamera, laptop, laporan survey, kuesioner untuk pengunjung dan panduan wawancara (pengelola, Pemerintah Daerah dan tokoh masyarakat), peta kawasan, informasi lainnya.

\section{Metode Pengambilan Data}

Metode pengambilan data Dalam penelitian pengambilan data di lapangan yang diperlukan sebagai data primer adalah data presepsi wisatawan dan masyarakat, manfaat social ekonomi terkait peluang kerja dan usaha yang ditimbulkan dalam kegiatan ekowisat. Data sekunder yang digunakan ialah data iklim yang diperlukan adalah potensi atraksi wisata, amenitas, aksebilitas, deskripsi wilayah, data penunjang, peta-peta dan keadaan social masyrakat (kependudukan, mata pencarian, pendidikan) serta data lain yang diperlukan.

\section{Metode Analisis Data}

Data yang diperoleh dianalisis secara deskriptif kuantitaif. Fakta dan sifat-sifat hubungan antar fenomena yang diteliti ditelaah dan dianalisis keterkaitannya satu sama lain. Hasil analisis disajikan secara akurat dengan mebuat deskripsi dan gambaran yang sistematis untuk mencari pemecahan masalah.

\section{Analisis Trend Wisatawan}

Analisis Trend wisatawan yang diperkirakan akan berkunjung kelokasi objek dan daya tarik wisata pada tahun-tahun mendatang dianalisis dengan menggunakan rumus sebagai berikut (Fadeli,2002)

$\mathrm{Ytn}=\mathrm{Yo}_{0}(\mathrm{I}+\mathrm{r})^{\mathrm{t}}$

Dimana :

Ytn $=$ Jumlah wisatawan pada waktu mendatang

Yo $=$ Jumlah wisatawan pada saat awal

$\mathrm{r}=$ Angka pertumbuhan $(\%)$ 
$\mathrm{t}=$ Waktu prediksi yang akan datang

\section{Analisis SWOT}

Data yang berkaitan dengan rancangan yang akan dikembangkan dilalakukan analisis SWOT. Hasil analisis tersebut akan dijadikan sebagai informasi yang dapat dijadikan sebagai strategi kebijakan dan pemodelan pengembangan ekowisata di Hutan Meranti Desa Sebelimbingan.

\section{HASIL DAN PEMBAHASAN}

\section{Hasil Pengamatan}

Tabel 2. Jumlah Pengunjung Ekowisata Hutan Meranti dari Juli 2016

\begin{tabular}{|l|l|l|l|}
\hline \multirow{2}{*}{ Bulan } & \multicolumn{2}{|l|}{ Jumlah } \\
\cline { 2 - 4 } & $\begin{array}{l}\text { Jumlah } \\
\text { Wisatawan }\end{array}$ & $\begin{array}{l}\text { Dalam } \\
\text { Negeri }\end{array}$ & $\begin{array}{l}\text { Luar } \\
\text { Negeri }\end{array}$ \\
\hline Juli & 461 & 145 & 32 \\
\hline Agustus & 2028 & 965 & 3 \\
\hline Oktober & 2154 & 996 & 0 \\
\hline November & 1630 & 777 & 0 \\
\hline Desember & 7359 & 2951 & 24 \\
\hline Januari & 7584 & 3468 & 8 \\
\hline Februari & 7269 & 2947 & 0 \\
\hline Jumlah & 28485 & 12249 & 67 \\
\hline Rata-rata & 4069,28 & 1749,85 & 9,57 \\
\hline Sumber : Dinas & &
\end{tabular}

Sumber : Dinas Lingkungn Hidup, 2017

Dilihat dari data 7 bulan terakhir terhitung dari diberlakukannya tarif tiket masuk ke kawasan Ekowisata Hutan Meranti, jumlah pengunjung setiap bulannya mengalami peningkatan yang sangat signifikan. Jumlah rat-rata pengunjung per bulan adalah sekitar 28485 orang dengan rata-rata tingkat pertumbuhan $95,79 \%$. Hal ini membuktikan bahwa Kawasan Ekowisata Hutan Meranti memiliki potensi dan daya tarik dalam bidang destinasi wisata alam.

Tabel 3. Prediksi Wisatawan di Ekowisata Hutan Meranti Bulan Maret s/d September

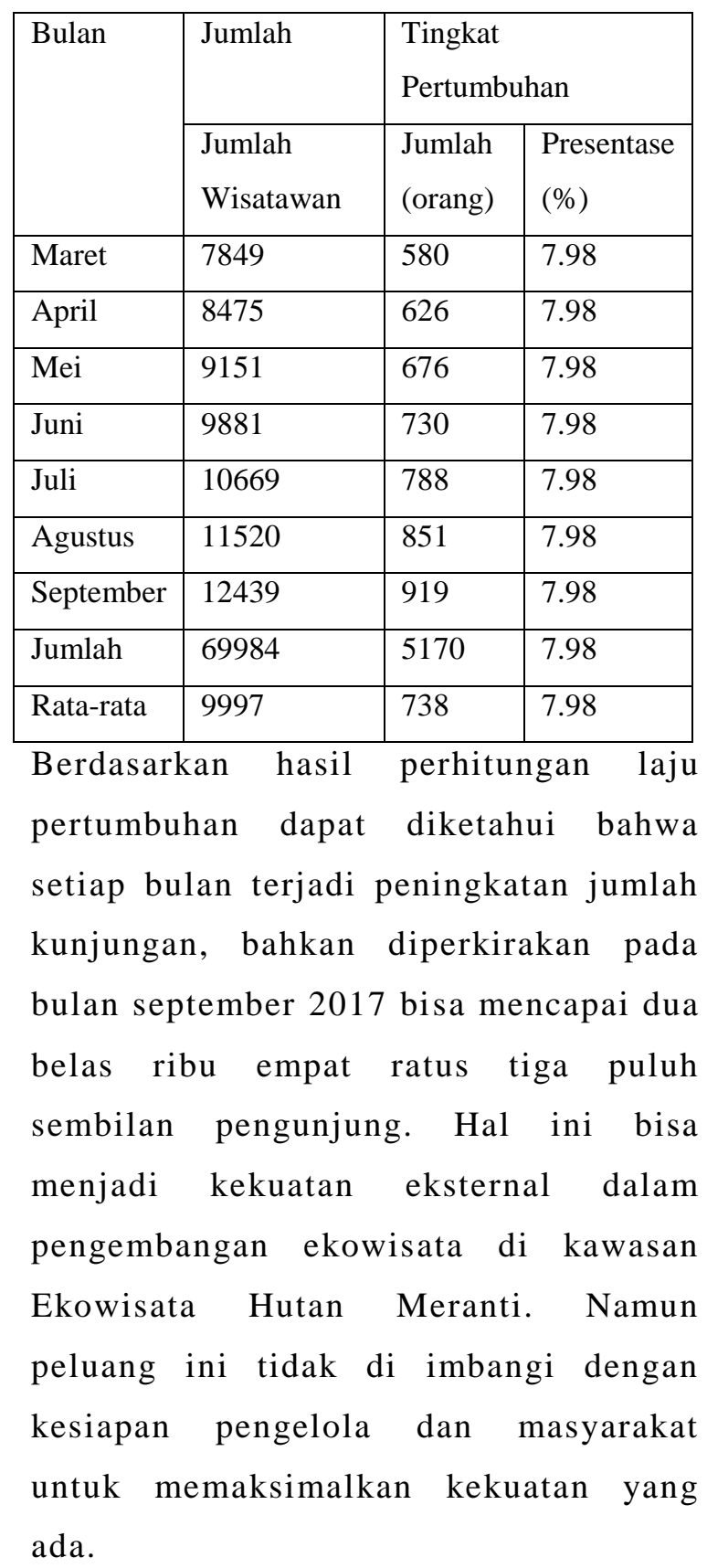

Tabel 4. Tabel Analis SWOT Penetapan Strategi

\begin{tabular}{|l|l|l|}
\hline \multirow{2}{*}{ No } & INTERNAL & \multicolumn{2}{|l|}{} \\
\cline { 2 - 3 } & $\begin{array}{l}\text { Kekuatan } \\
\text { (Strenghts) }\end{array}$ & $\begin{array}{l}\text { Kelemahan } \\
\text { (Weaknesses) }\end{array}$ \\
\hline 1 & $\begin{array}{l}\text { Kawasan yang luas } \\
\text { dan telah memiliki }\end{array}$ & $\begin{array}{l}\text { Rendahnya } \\
\text { kegiatan } \\
\end{array}$ \\
& tatabatas yang jelas & pemasaran, \\
\hline
\end{tabular}




\begin{tabular}{|c|c|c|}
\hline & & $\begin{array}{l}\text { kegiatan promosi } \\
\text { yang dilakukan } \\
\text { kurang efektif dan } \\
\text { selama ini promosi } \\
\text { hanya melalui } \\
\text { pembicaraan yang } \\
\text { terjadi dari mulut } \\
\text { ke mulut }\end{array}$ \\
\hline 2 & \begin{tabular}{lr}
\multicolumn{2}{l}{ Memiki keindahan } \\
panorama alam \\
yang disebabkan \\
kondisi \\
sekitar kawan \\
yang masih alami \\
dan sejuk
\end{tabular} & $\begin{array}{l}\text { Lemahnya } \\
\text { pengadaan fasilitas, } \\
\text { kondisi fasilitas } \\
\text { yang ada sekarang } \\
\text { ini sangat minim } \\
\text { bahkan bisa } \\
\text { dikatakan tidak ada. }\end{array}$ \\
\hline 3 & $\begin{array}{lr}\text { Terdapat objek } \\
\text { wisata yang masih } \\
\text { bisa dikembangkan } \\
\text { seperti } \\
\text { perkemahan }\end{array}$ & $\begin{array}{l}\text { Pelibatan } \\
\text { masyarakat kurang } \\
\text { optimal, dalam hal } \\
\text { ini masyarakat } \\
\text { kurang dilibatkan } \\
\text { dalam pengelolaan } \\
\text { di kawasan wisata. }\end{array}$ \\
\hline 4 & $\begin{array}{lr}\text { Dukungan } & \text { respon } \\
\text { positif } & \text { dari } \\
\text { masyarakat } & \text { sekitar } \\
\text { untuk ikut } & \text { berpartisipasi } \\
\text { dalam pengelolaan } \\
\text { dan } \\
\text { pengembangaan } \\
\text { kawasan. }\end{array}$ & $\begin{array}{l}\text { Masyarakat belum } \\
\text { seluruhnya } \\
\text { menikmati dampak } \\
\text { positif dari } \\
\text { keberadaan } \\
\text { kawasan Ekowisata } \\
\text { Hutan Meranti }\end{array}$ \\
\hline 5 & $\begin{array}{l}\text { Paket wisata yang } \\
\text { ditawarkan relative } \\
\text { murah }\end{array}$ & $\begin{array}{lr}\text { Belum } & \text { adanya } \\
\text { fasilitas } & \text { penunjang } \\
\text { seperti } & \text { tempat } \\
\text { ibadah } & \end{array}$ \\
\hline \multicolumn{3}{|c|}{ EKSTERNAL } \\
\hline & $\begin{array}{l}\text { Peluang } \\
\text { (Opportunities) }\end{array}$ & $\begin{array}{l}\text { Ancaman } \\
\text { (Threats) }\end{array}$ \\
\hline 1 & $\begin{array}{l}\text { Dukungan dari } \\
\text { masyarakat dan } \\
\text { tokoh-tokoh } \\
\text { masyarakat sekitar } \\
\text { kawasan, terutama } \\
\text { dalam } \\
\text { pengembangan } \\
\text { kawasan wisata. }\end{array}$ & $\begin{array}{l}\text { Ancaman bencana } \\
\text { alam, berupa } \\
\text { musim kemarau } \\
\text { akan } \\
\text { mengakibatkan } \\
\text { mudah terbakar }\end{array}$ \\
\hline
\end{tabular}

\begin{tabular}{|c|c|c|}
\hline 2 & $\begin{array}{l}\text { Peluang } \\
\text { pendapatan, dapat } \\
\text { menciptakan } \\
\text { kesempatan kerja } \\
\text { dan berusaha bagi } \\
\text { masyarakat } \\
\text { sehingga secara } \\
\text { tidak langsung } \\
\text { dapat } \\
\text { meningkatkan } \\
\text { pendapatan } \\
\text { masyarakat karena } \\
\text { tidak tergantung } \\
\text { pada satu jenis } \\
\text { mata pencaharian } \\
\text { serta dapat } \\
\text { meningkatkan } \\
\text { pendapatan daerah. }\end{array}$ & $\begin{array}{lr}\text { Ancaman } & \text { berupa } \\
\text { pohon } & \text { tumbang } \\
\text { ketika } & \text { angina } \\
\text { kencang dikawasan } \\
\text { hutan meranti }\end{array}$ \\
\hline 3 & $\begin{array}{l}\text { Terciptanya iklim } \\
\text { investasi, dapat } \\
\text { menarik minat } \\
\text { pengusaha } \\
\text { ekowisata untuk } \\
\text { bekerjasama } \\
\text { dengan para } \\
\text { stakeholder dalam } \\
\text { pengembangan } \\
\text { pembangunan } \\
\text { pariwisata yang } \\
\text { berkelanjutan. }\end{array}$ & \begin{tabular}{l}
\multicolumn{2}{l}{ Berkurangnya } \\
jenis-jenis satwa \\
yang \\
dikarenakan tidak \\
adanya perawatan \\
khusus \\
pengelola.
\end{tabular} \\
\hline
\end{tabular}




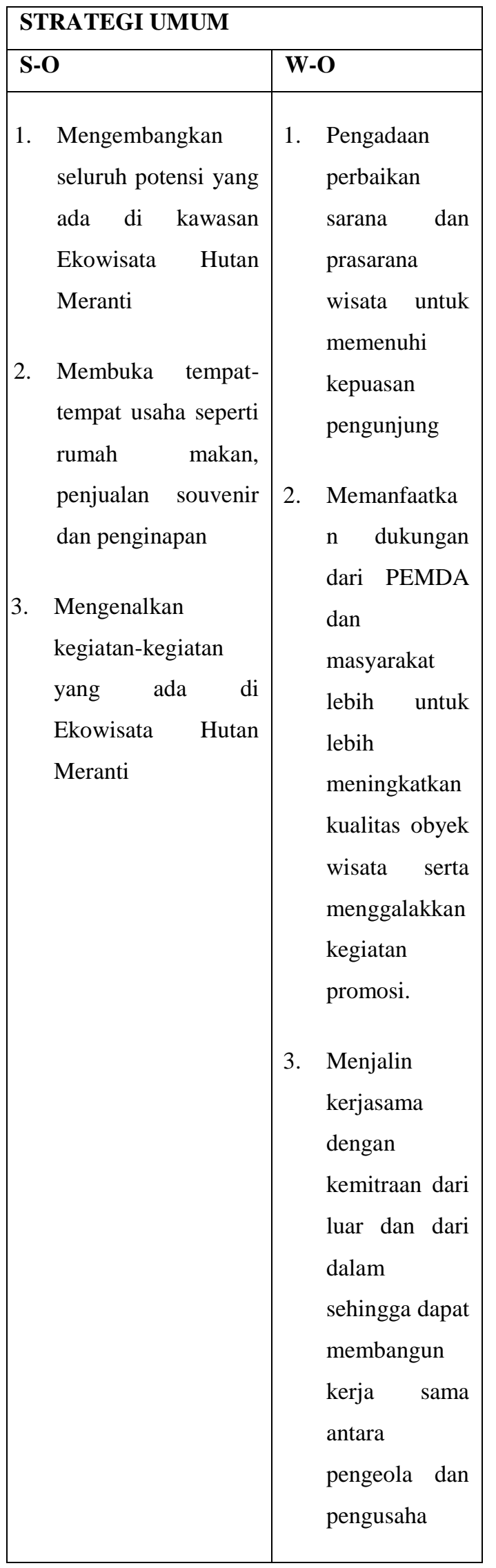

\section{Pembahasan}

Berdasarkan hasil analisis SWOT di Ekowisata Hutan Meranti dan permasalahan yang ada, maka perlu adanya rencana pengelolaan dan pengembangan di kawasan tersebut. Hasil analisis SWOT dari kekuatan, peluang, kelemahan dan ancaman yang ada menunjukkan bahwa diperlukannya strategi pengembangan dan pengelolaan. Adapun strategi yang dibuat antara lain :

\section{a. Penguatan konsep ecotourism bagi}

\section{Ekowisata Hutan Meranti}

Ekowisata Hutan Meranti memiliki potensi wisata alam yang sangat menarik perlu dikembangkan secara lebih serius oleh Pemerintah. Hal ini dilakukkan demi meningkatkan nilai ekonomis wilayah ini bagi penguatan ekonomi masyarakat sekitar. Namun untuk mengurangi dampak yang

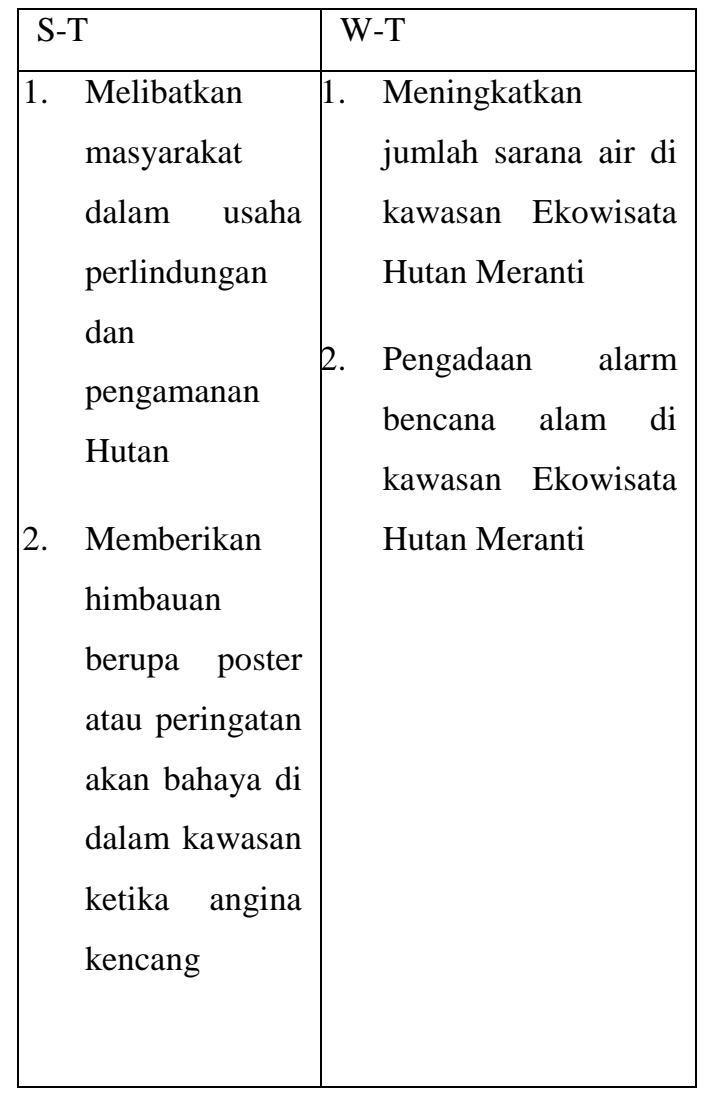


negatif terhadap kerusakan lingkungan maka diperlukan sebuah upaya khusus untuk menanggulanginya. Salah satu konsep yang tepat untuk mengatasi masalah ini adalah dengan mengembangkan konsep Ecotourism di Ekowisata Hutan Meranti. Dalam konteks ini maka Ekowisata Hutan Meranti akan diarahkan sedemikian rupa agar pengembangannya tidak menganggu atau selaras dengan upaya konservasi lingkungan serta berdampak positif bagi pengembangan ekonomi lokal. Pengembangan ekonomi lokal dilakukkan selain untuk menopang keberlanjutan konservasi juga diperlukan untuk mendorong kesejahteraan masyarakat sekitar. Namun dalam mengembangkan dan menguatkan konsep Ecotourism untuk mengembangkan ekonomi lokal diperlukan sebuah pemahaman yang tepat pada masyarakat dan pemerintah lokal. Hal ini dilakukkan agar pemerintah lokal dan masyarakat bisa berperan aktif dan menjadi stakeholder yang berkepentingan terhadap pengembangan wilayah ini. Salah satunya adalah dengan mengembangkan sebuah unit-unit ekonomi (BUMDES-Badan Usaha Milik Desa) dan Koperasi untuk mendukung aktivitas dan kebutuhan para wisatawan, mulai dari unit usaha makanan, Souvenir, Penginapan, Parkir hingga Pemandu wisata.

\section{b. Penataan kembali ruang untuk kegiatan} ekowisata.

Penataan kembali ruang untuk kegiatan ekowisata perbaikan insfrastruktur, sarana dan prasana penunjang seperti jaringan air bersih, pembangunan WC atau kamar mandi dipuncak meranti, musholla sistem pengolahan dan pembuangan sampah, serta unit usaha penunjang kebutuhan wisatawan.

c. Mendorong linkage dengan travel unit (agen perjalanan).

Pengembangan suatu kawasan wisata tidak bisa dilepaskan dari keberadan para pemadu wisata dan agen perjalanan. Karena pemandu wisata dan agen wisata merupakan ujung tombak terdepan yang langsung berhubungan dengan para wisatwan atau stakeholder, sehingga untuk lebih mudah dalam mengembangkan suatu kawasan ekowisata maka diperlukan partisipasi mereka secara lebih jauh. pemandu wisata dan agen perjalanan bisa dikontrol. Selain itu, keinginan dari para wisatawan dapat lebih mudah ditangkap, sehingga pengembangan ekowisata lebih terarah dan sesuai dengan keinginan stakeholder. Namun dalam pengembangan hubungan dengan agen perjalanan diperlukan sebuah kesepakatan tentang konsep Ecotourism yang dikembangkan di wilayah ini. Hal ini dimaksudkan agar tawaran paket wisata yang diberikan tidak menggangu upaya konservasi alam yang juga dilakukkan di wilayah ini. Selain itu pihak pemandu perjalanan juga diharapkan tidak memisahkan diri untuk kepentingan pemberdayaan masyarakat lokal dalam mendukung Ekowisata.

d. Mendorong partisipasi dan pemberdayaan masyarakat Wisata.

Masyarakat lokal sebenarnya bukanlah hambatan bagi pengembangan Ekowisata, karena peran mereka seharusnya tidak 
terpisahkan dalam program-program wisata.

Pengelolaan berbasis masyarakat ini merupakan salah satu pendekataan pengelolaan alam yang meletakkan pengetahuan dan kesadaran lingkungan masyarakat lokal sebagai dasar pengelolaanya. Ditambah adanya transfer diantara generasi yang menjadikan pengelolaan menjadi berkesinambungan menjadikan cara inilah yang paling efektif, dibanding cara yang lainya. Secara umum sudah dibahas sebelumnya bahwa pengelolaan sumberdaya wilayah pesisir dan lautan efektif adalah yang berbasis pada masyarakat. Nikijuluw (1994) berpendapat pengelolaan berbasis masyarkat merupakan salah satu pendekataan pengelolaan alam yang meletakkan pengetahuan dan kesadaran lingkungan masyarakat lokal sebagai dasar pengelolaanya. Ditmabah adanya transfer diantara generasi yang menjadikan pengelolaan menjadi berkesinambungan menjadikan cara inilah yang paling efektif, dibanding cara yang lainya. Namun, masyarkat juga jangan sampai dilepaskan sendirian untuk mengelola semuanya. Karena sudah diketahui bersama, bahwa salah satu masalah utama yang dihadapi dalam pengelolaan ekowisata di Indonesia adalah masalah kualitas Sumber Daya Manusia SDM), karena ketidakmerataan pendidikan yang diperoleh. Salah satu hal yang bisa dilakukan dengan melibatkan pemerintah lokal dalam pengeloalaan.

\section{e. Mendorong unit-unit usaha yang strategis.}

Dengan semakin berkembangnya kawasan Hutan Meranti sebagai tempat Ekowisata, maka kebutuhan akan unit-unit usaha penyokong juga diperlukan seperti tempat penginapan, tempat parkir, usaha souvenir, toko serba ada (perancangan). Semua unit-unit usaha ini diharapkan dapat berada di wilayah Desa Sebelimbingan, karena diperlukan untuk mempertahankan kemurnian alam hayati dan sisi naturalisme yang tinggi. Dalam konteks pengembangan unit-unit usaha juga diperlukan sebuah bentuk kelembagaan yang baik dengan mengembangkan sisi sosial ekonomi secara bersamaan (social enterpreneurship) seperti konsep Koperasi dan BUMDES (Badan Usaha Milik Desa).

\section{f. Melakukan promosi yang gencar.}

Berkembangnya kawasan Ekowisata Hutan Meranri akan semakin baik jika promosi yang dilakukkan juga gencar, hal ini dilakukkan guna menanamkan image wisata yang kuat di wilayah Ekowisata Hutan Meranti. Promosi yang gencar selain dapat dikaitkan dengan program-program yang ada dalam agen perjalan juga dapat dilakukkan dengan mempromosikannya melalui website.

\section{KESIMPULAN}

Dari penelitian yang telah dilakukan dapat disimpulkan bahwa:

1) Kawasan Ekowisata Hutan Meranti memiliki potensi untuk lebih dikembangkan lagi, hal ini dibuktikan dari adanya beberapa lokasi yang masih belum dikembangkan dengan baik sehingga sangat diperlukan dukungan 
dari pemerintah dan penduduk setempat

2) Seluruh masyarakat mendukung adanya pengembangan dan pemberdayaan di Desa Sebelimbingan, hal ini dilatar belakangi oleh motivasi masyarakat untuk dapat meningkatkan taraf hidup masyarakat

\section{SARAN}

1) Mengembangkan seluruh potensi yang ada di kawasan Ekowisata Hutan Meranti

2) Mengenalkan kegiatan-kegiatan yang ada di Ekowisata Hutan Meranti

3) Pengadaan perbaikan sarana dan prasarana wisata untuk memenuhi kepuasan pengunjung

\section{DAFTAR PUSTAKA}

Fandeli. C, 2001. Dasar-Dasar Manajemen

Kepariwisataan Alam. Liberty. Yogyakarta. 


\section{Pendahuluan}

Taman Nasional Meru Betiri merupakan kawasan konservasi yang memiliki potensi keanekaragaman flora dan fauna yang sangat tinggi. Taman nasional ini merupakan perwakilan dari tipe ekosistem hutan hujan tropika dataran rendah. Kawasan Taman Nasional Meru Betiri telah teridentifikasi flora sebanyak 518 jenis, terdiri 15 jenis yang dilindungi dan 503 jenis yang tidak dilindungi. Salah satu jenis tumbuhan yang dilindungi tersebut adalah Rafflesia zollingeriana Kds.

Rafflesia adalah tumbuhan yang unik karena ukuran bunganya yang besar, serta kehadirannya yang baru disadari ketika kuncup bunganya mekar. Rafflesia tersebar di Taman Nasional Meru Betiri Jawa Timur dengan populasi rafflesia yang umumnya kecil (Nais, 2001). Persebaran populasi dalam kawasan yang luas dan masa hidup yang pendek, mengakibatkan sulitnya pendataan secara berkelanjutan. Pendataan rafflesia secara inventore akan memudahkan pengambilan keputusan yang sesuai untuk kepentingan pelestarian rafflesia di Taman Nasional Meru Betiri, JawaTimur.

Kehadiran vegetasi pada suatu landscape akan memberikan dampak positif bagi keseimbangan ekosistem dalam kelestarian rafflesia. Rafflesia yang hidup di ekosistem hutan hujan tropis memang sangat membutuhkan kelembaban yang sangat tinggi yaitu 80-90\% (Zuhud, 1989). Komposisi vegetasi tersebut memang akan sangat membantu keseimbangan ekosistem untuk menunjang pertumbuhan rafflesia. Meskipun secara umum kehadiran vegetasi membeikan dampak positif bagi keseimbangan ekosistem, namun sering juga kehadiran vegetasi menimbulkan persaingan antar vegetasi.

Persaingan vegetasi pada suatu landscape sangat bervariasi, mulai dari persaingan untuk mendapatkan unsur hara, persaingan luas bidang dasar pada tapak, persaingan mendapatkan cahaya, dan lain-lain. Melihat berbagai dampak yang ditimbulkan oleh kehadiran vegetasi tersebut, khususnya pada kajian habitat rafflesia ini, studi analisis vegetasi sangat diperlukan untuk mengetahui komposisi vegetasi dan jenis apakah yang sangat mempengaruhi kehidupan dari rafflesia. Struktur dan komposisi vegetasi pada suatu landscape dipengaruhi oleh komponen ekosistem lainnya yang saling berinteraksi, sehingga vegetasi yang tumbuh secara alami (Setiadi, 1984). Oleh karena itu, diperlukan penelitian mengenai habitat rafflesia yang terdapat di kawasan Taman Nasional Meru Betiri.

\section{Bahan dan Metode}

\section{Lokasidan Waktu Penelitian}

Penelitian dilaksanakan pada Januari 2017 selama kurun waktu satu bulan di Blok Krecek, Resort Bandealit, STPN Wilayah II, Balai Taman Nasional Meru Betiri. Secara administrasi, lokasi penelitian ini terletak diKecamatan Ambulu, Kabupaten Jember, Provinsi Jawa Timur. Lokasi Penelitian dapat dilihat pada Gambar 1. 


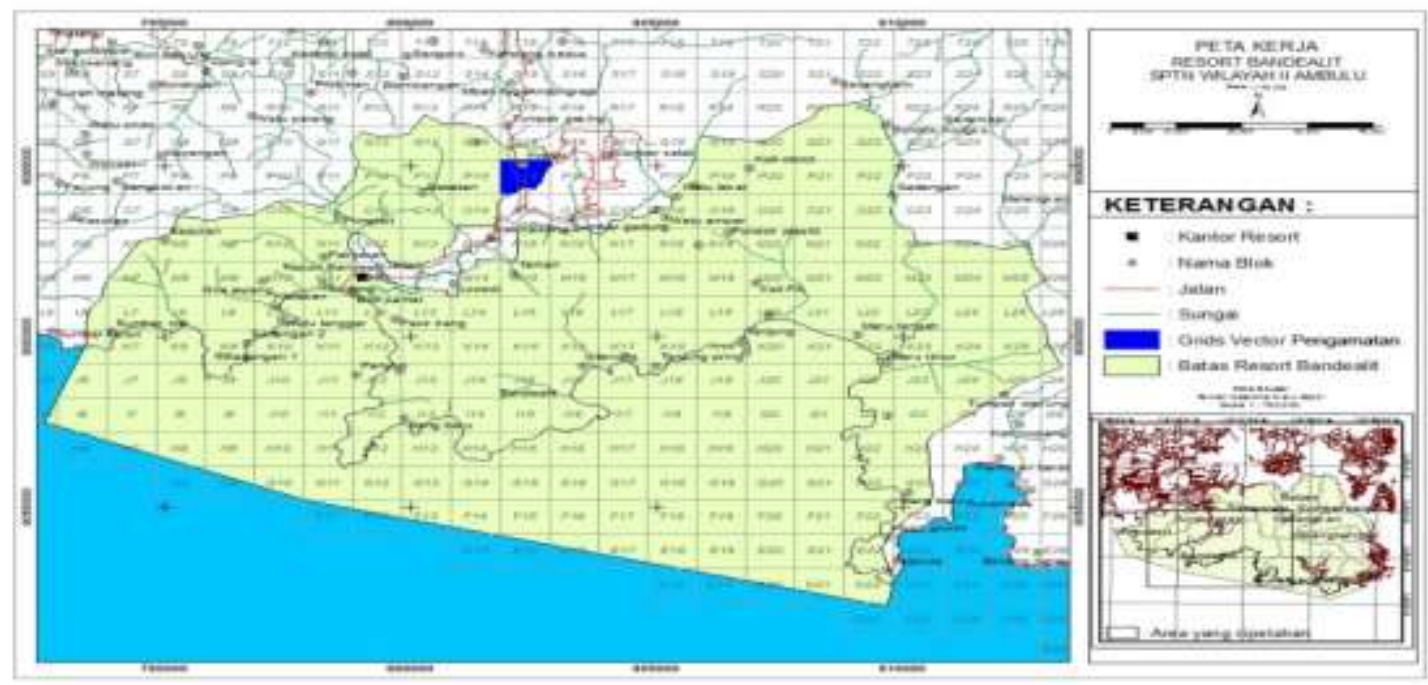

Gambar 1. Peta Lokasi Penelitian

\section{Metode Pengumpulan Data}

Metode pengambilan data yang digunakan untuk mengetahui persebaran $R$. zollingeriana Kds.yaitu metode sensus, dengan cara penelusuran terhadap akar dan batang inang tetrastigma. Sedangkan untuk mengetahui kondisi habitat, digunakan metode sample plot, dengan ukuran plot 20 × 20 meter tanpa menggunakan intensitas sampling. Data yang diambil dalam plot meliputi 4 tingkat hidup pohon yaitu semai, pancang, tiang dan pohon. Parameter yang diukur antara lain jumlah individu per spesies; nama spesies (local dan ilmiah); serta tinggi dan diameter setinggi dada. Plot analisis vegetasi 20x20 meter dapat dilihat pada Gambar 2.

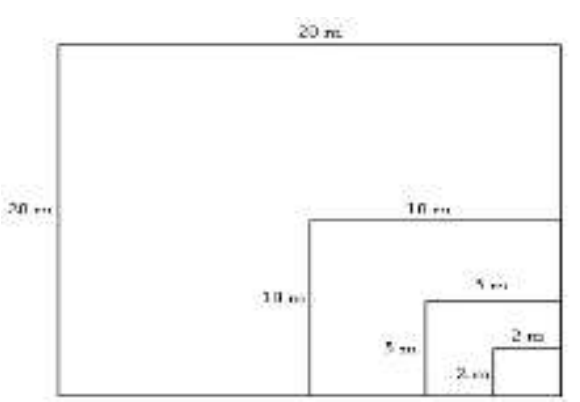

Gambar 2. Plot AnalisisVegetasi
Keterangan:

1) Petak ukur $2 \times 2 \mathrm{~m}$ untuk data semai (tinggi $<1,5 \mathrm{~m}$ )

2) Petak ukur $5 \times 5 \mathrm{~m}$ untuk data pancang (tinggi $1,5-3 \mathrm{~m}$ dan diameter $<15 \mathrm{~cm}$ )

3) Petak ukur $10 \times 10 \mathrm{~m}$ untuk data tiang (diameter $15-30 \mathrm{~cm}$ )

4) Petak ukur $20 \times 20 \mathrm{~m}$ untuk data pohon (diameter $>30 \mathrm{~cm}$ )

Data abiotic juga diperlukan dalam penelitian ini untuk mengetahui kondisi habitat ditinjau dari sisi abiotik. Data yang diambil yaitu data kondisi tanah antara lain data jenis tanah, kelembaban tanah, kelerengan, ketebalan seresah, dan $\mathrm{pH}$ tanah.

\section{Analisis Data}

a. Analisis Vegetasi

Analisis vegetasi dilakukan untuk mendeskripsikan persebaran dan kondisi habitat ditinjau dari sisi biotik. Selain itu, untuk mendeskripsikan kondisi habitat ditinjau dari sisi abiotic dilakukan dengan mendeskripsikan kondisi tanah di lokasi penelitian. Analisis vegetasi menggunakan perhitungan Indeks Nilai Penting (INP), Indeks Kesamaan, Indeks Keragaman, Indeks Kekayaan, dan Indeks Kemerataan.

- Kerapatan (batang/ ha) = Jumlah individu jenis ke-i Luas total petak contoh 
- KerapatanRelatif $(\%)=$

Kerapatan jenis ix 100\%

Kerapatan total

- Frekuensi =

Frekuensi jenis i x 100\%

Frekuensi total

- FrekuensiRelatif $(\%)=$ Jumlah petak contoh ditemukan jenis i jumlah total petak contoh

- Dominansi $=$

Luas bidang dasar (LBDS) jenis i

Luas petak contoh

- DominansiRelatif $(\%)=$

Dominansi jenis i x $100 \%$

Dominansi total

- Indeks Nilai Penting = $\mathrm{KR}+\mathrm{FR}+\mathrm{DR}$

(Bismark, 2011).

Vegetasi yang berada di plot non rafflesia dan rafflesia dapat dihitung dengan menggunakan Indeks Kesamaan (Ludwig-Reynold).

$$
\frac{2 C}{A+B}
$$

Keterangan:

$\mathrm{C}=$ Jumlah spesies yang sama dan terdapat pada kedua komunitas

$A=$ Jumlah spesies di dalam plot rafflesia

$\mathrm{B}=$ Jumlah spesies di dalam plot non rafflesia

Keanekaragaman jenis ditentukan dengan rumus

Indeks Keanekaragaman Shannon-Wiener:

$$
H^{\prime}=\sum_{i=1}^{n}\left\lceil\frac{\mathrm{ni}}{\mathrm{N}} \ln \frac{\mathrm{ni}}{\mathrm{N}}\right\rceil
$$

$$
\mathrm{H}^{\prime}=\sum \text { pi In pi }
$$

$\mathrm{Pi}=\frac{\mathrm{nI}}{\mathrm{N}}$

Keterangan:

H'= Indeks Keanekaragaman Shannon-Wiener

$\mathrm{ni}=$ jumlah individu jenis ke-n

$\mathrm{N}=$ total jumlah individu
Adapun nilai H' adalah sebagai berikut:

$\mathrm{H}^{\prime}<1=$ tingkat keanekaragaman jenis rendah

H'1-3 = tingkat keanekaragaman jenis sedang

$\mathrm{H}^{\prime}>3=$ tingkat keanekaragaman jenis tinggi

(Bismark, 2011).

Kekayaan jenis vegetasi ditentukan dengan menggunakan Indeks Kekayaan (LudwigReynold).

$$
\mathrm{R}=\frac{S-1}{\ln (N)}
$$

Keterangan:

$\mathrm{R}=$ Indeks Kekayaan Jenis

$\mathrm{S}=$ Jumlah Jenis

$\mathrm{N}=$ Jumlah Total Individu

Kemerataan jenis vegetasi ditentukan dengan menggunakan Indeks Kemerataan (LudwigReynold).

$$
\mathrm{E}=\frac{H r}{\ln (S)}
$$

Keterangan:

$\mathrm{E}=$ Indeks Kemerataan Jenis

$\mathrm{H}^{\prime}=$ Indeks Keanekaragaman Jenis

$\mathrm{S}=$ Jumlah Jenis

(Prasetyo, 2016)

b. Analisis Asosiasi

Analisis untuk mengetahui asosiasi antar spesies menurut Sugianto (1994), yaitu:

1) menentukan jenis-jenis vegetasi penyusun hutan yang mempunyai Indeks Nilai Penting $10 \%$ atau lebih; dan

2) melakukan perhitungan untuk mengetahui adanya asosisasi antara jenis vegetasi dengan menggunakan tabel kontingensi $2 \mathrm{x}$ 2 meter, yaitu dimulai dengan jenis yang mempunyai Indeks Nilai Penting tertinggi. Selanjutnya hasil $\mathrm{N}$ dari tabel kontingensi 2 x 2 meter yang disajikan pada Tabel 1 dan dilakukan pengujian dengan menggunakan uji chi square $\left(\mathrm{x}^{2}\right)$. 
Tabel 1. TabelKontingensi $2 \times 2$ meter

\begin{tabular}{|c|c|c|c|}
\hline $\begin{array}{c}\text { Spesies A } \\
\text { Spesies B }\end{array}$ & Ada & $\begin{array}{c}\text { Tidak } \\
\text { ada }\end{array}$ & Jumlah \\
\hline $\begin{array}{c}\text { Ada } \\
\text { Tidak }\end{array}$ & $\boldsymbol{a}$ & $b$ & $m=a+b$ \\
\hline Jumlah & $r=a+c$ & $s=b+d$ & $\begin{array}{c}N=a+b \\
+c+d\end{array}$ \\
\hline
\end{tabular}

Keterangan: (a: Plot keberadaan spesies A dan spesies B; b: Plot ketiadaan spesies A dan keberadaan spesies B; c: Plot keberadaan spesies A dan ketiadaan spesies B; d: Plot ketiadaan spesies A dan ketiadaan spesies B)

Analisis terhadap asosiasi juga dilakukan berdasarkan ukuran kekuatan dengan menghitung Indeks Ochial, Indeks Dice, dan Indeks Jaccard. Menurut Indriyanto (2006), dari ketiga indeks tersebut cenderung bernilai 0 saat tidak ada asosiasi dan bernilai 1 saat asosiasi maksimum.

- Indeks Ochiai (OI)

Indeks ochiai (OI) dijelaskan dalam rata-rata geometrik $\mathrm{a} / \mathrm{m}$ dan $\mathrm{a} / \mathrm{r}$ yaitu:

$$
\frac{a}{\sqrt{a+b \sqrt{a+c}}}
$$

\section{- Indeks Dice (DI)}

Indek dice (DI) dijelaskan dalam rata-rata keseimbangan $\mathrm{a} / \mathrm{m}$ dan $\mathrm{a} / \mathrm{r}$ yaitu:

$$
\frac{2 a}{2 a+b+c}
$$

-Indeks Jaccard (JI)

Indeks Jaccard (JI) adalah proporsi nilai dari plot, dimana spesies muncul sebagai nilai total dari plot saat salah satu dari jenis sesies ditentukan:

$$
\frac{a}{2 a+b+c}
$$

Jika nilai indeks mendekati angka 1 maka hal tersebut menunjukkan bahwa hubungan antara kedua spesies tumbuhan tersebut semakin kuat.

\section{Hasil dan Diskusi}

Persebaran dan Habitat Rafflesia zollingeriana Kds.

Hasil pengamatan di plot permanen rafflesia Blok Krecek, Resort Bandealit, Taman Nasional Meru Betiri diperoleh 4 individu $R$. zollingeriana Kds. dengan kondisiyakni, 3 individu knop segar dan 1 individu mekar mati. Rafflesia yang ditemukan hanya mengelompok pada plot I, dimana menandakan bahwa persebaran rafflesia yang ditemukan tidak merata pada seluruh plot karena hanya berada dalam satu plot saja.Menurut Lestari (2013), rendahnya populasi dan kematian bunga rafflesia disebabkan oleh dua hal yaitu tergantungya distribusi nutrisi dari inang kepada knop rafflesia dan adanya gangguan dari satwa liar atau manusia.Zuhud (1988) juga menyebutkan bahwa kematian bunga rafflesia disebabkan oleh ancaman manusia yang memungut knop untuk dijadikan

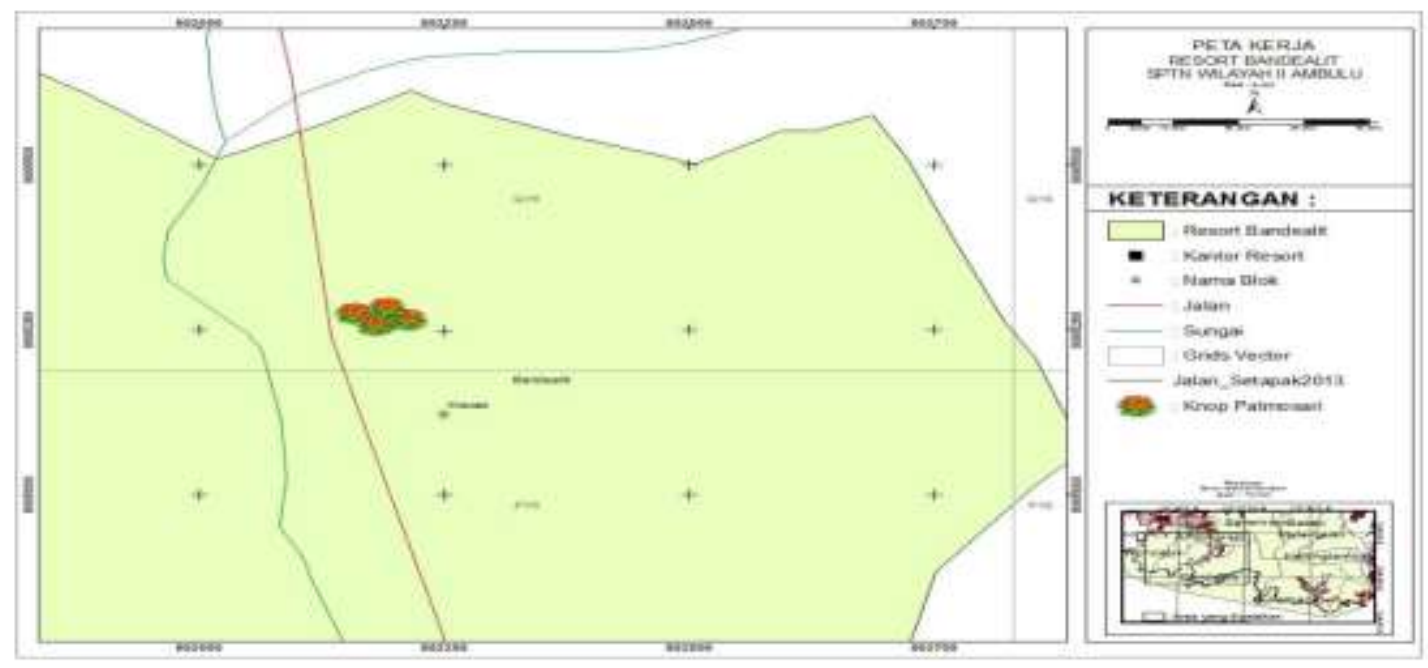

Gambar 3. Peta Persebaran $R$. zollingeriana. Kds di Plot Permanen 
bahan baku jamu. Persebaran rafflesia dapat dilihat

Karakteristik habitat rafflesia dapat ditinjau dari kondisi komponen biotik dan abiotik. Kondisi komponen biotik meliputi kondisi inang dan kondisi vegetasi. Inang dari rafflesia yaitu tetrastigma. Tetrastigma termasuk tumbuhan berbiji yang melakukan perkembangbiakan secara generatif menggunakan biji. Namun, pada plot pengamatan ditemukan tetrastigma tumbuh secara vegetatif. Hasilpengamatanmenunjukkan bahwa hanya ada 2 individu inang tetrastigma yang ditumbuhi oleh rafflesia.Tumbuhan yang dipanjati oleh tetrastigma pada plot pengamatan merupakan pohon yang bertajuk tinggi sehingga memberikan kesempatan bagi tetrastigma untuk memperoleh pada Gambar 3.

cahaya untuk keberlangsungan hidupnya. Selain kondisi inang, kelangsungan hidup rafflesia juga dipengaruhi oleh kondisi vegetasi di sekitarnya. Hasil pengamatan terkait kondisi vegetasi menunjukkan bahwa jumlah spesies tertinggi adalah jerukan (Polyalthiaruphii L.) dengan jumlah individu sebanyak 48 individu, sedangkan spesies terendah adalah suren (Tonnasureni Bl. Merill.) dengan jumlah individu 1 individu saja. Jumlah individu keseluruhan sebanyak 385 individu yang tersebar merata di setiap petak ukur. Berikut grafik terkait jumlah individu dari setiap spesies yang ditemukan disajikan pada Gambar 4.

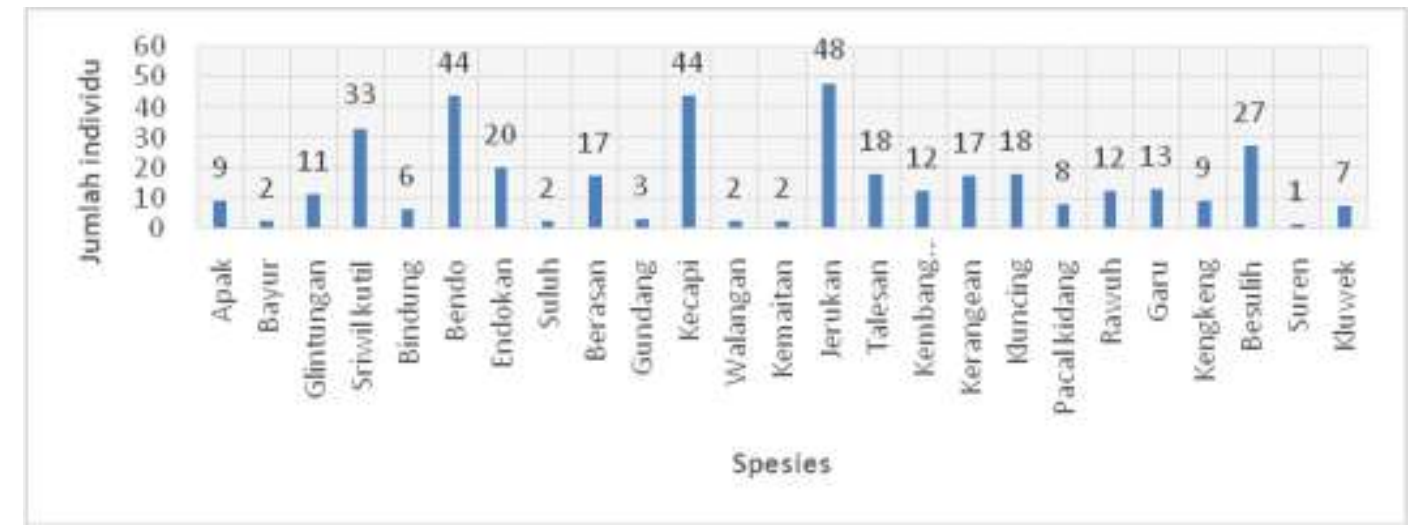

Gambar 4. Grafik Jumlah Individu Setiap Spesies di Lokasi Pengamatan

Berdasarkan hasil perhitungan Indeks Nilai Penting menunjukkan penurunan dari tingkat semai menuju pohon. Hal ini dikarenakan adanya persaingan antar maupun sesama jenis individu. Persaingan atau kompetisi ini disebabkan jenis-jenis tersebut mempunyai kebutuhan hidup yang sama akan unsur hara, sedangkan sumber-sumber yang mendukung kebutuhan hidup itu sendiri terbatas. Berikut grafik Indeks Nilai Penting spesies disajikan pada

Gambar 5.

\begin{tabular}{|c|c|c|c|c|c|}
\hline \multirow{9}{*}{ 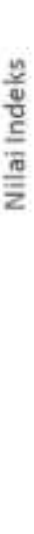 } & \multirow{9}{*}{$\begin{array}{r}100 \\
90 \\
80 \\
70 \\
60 \\
50 \\
40 \\
30 \\
20 \\
10\end{array}$} & \multicolumn{3}{|c|}{88.74} & \\
\hline & & 71.84 & & & \\
\hline & & & & 59.67 & \\
\hline & & & & & 39.18 \\
\hline & & & & & \\
\hline & & & & 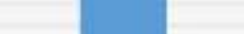 & 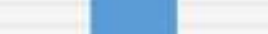 \\
\hline & & Polyalthia ruphii L. & Polyalthiaruphii L & Polyalthia ruphii L & $\begin{array}{c}\text { Artocarpus elasticus } \\
\text { Reinw. Ex BL. }\end{array}$ \\
\hline & & Jerukan & Jerukan & Jerukan & Bendo \\
\hline & & Semai & Pancang: & Tiang & Pohon \\
\hline
\end{tabular}

Gambar 5. Indeks Nilai Penting Spesies Tertinggi 
Selain Indeks Nilai Penting, kondisi habitat juga ditinjau dari keragaman, kekayaan, kemerataan, dankesamaan spesies.Jenis dan jumlah spesies yang ada di plot permanen rafflesia Blok Krecek cukup tinggi. Adapun nilai keragaman menunjukkan bahwa tingkat keragaman di plot permanen rafflesia blok Krecek masih tergolong sedang karena nilai indeks keragaman tidak mencapai nilai 3 atau lebih.Keragaman suatu komunitas juga dilihat dari penyebaran spesies dalam komunitas tersebut yang dinyatakan dalam indeks kemerataan (Ludwig, 1988). Apabila nilai indeks mendekati 0 maka spesies dalam suatu komunitas tidak tersebar merata, sebaliknya apabila nilai indeks mendekati 1 maka spesies dalam suatu komunitas tersebar merata. Kemerataan pada plot permanen rafflesia Blok Krecek termasuk tidak terlalu merata karena nilai indeks kemerataannya tidak mencapai 1 . Berdasarkan keseluruhan indeks, menunjukkan bahwa habitat vegetasi pada plot permanen rafflesia Blok Krecek cukup baik, yakni dari 12 plot yang telah dibuat, rafflesia hanya ditemukan pada 1 plot saja, dengan demikian plot tersebut dapat dibagi menjadi 2 tipe, yaitu plot rafflesia (plot ditemukannya rafflesia) dan plot non rafflesia (plot tidak ditemukannya rafflesia). Persamaan komposisi spesies pada kedua tipe plot tersebut dapat dilihatdengancara menghitung indeks kesamaan.Perbedaan komposisi spesies antara plot rafflesia dan non rafflesia sangat jelas berbeda, khususnya pada tingkat pertumbuhan anakan pohon (semai dan pancang) yang memiliki nilai lebih rendah dari pada pada tingkat pertumbuhan tiang dan pohon. Hal ini selaras dengan hasil penelitian Ali (2014) yang menunjukkan bahwa indeks kesamaan komposisi spesies rafflesia menunjukkan nilai indeks yang rendah pada tingkat pertumbuhan anakan pohon (semai dan pancang) dan menunjukkan nilai indek tinggi pada tingkat pertumbuhan tiang dan pohon. Persaingan antara tumbuhan bawah dan anakan pohon untuk memperoleh zat-zat organik dan anorganik di dalam tanah mengakibatkan rendahnya nilai indeks pada tingkat pertumbuhan anakan pohon. Nilai Indeks Keragaman, Kekayaan, Kemerataan, dan Kesamaan disajikan pada Gambar 6.

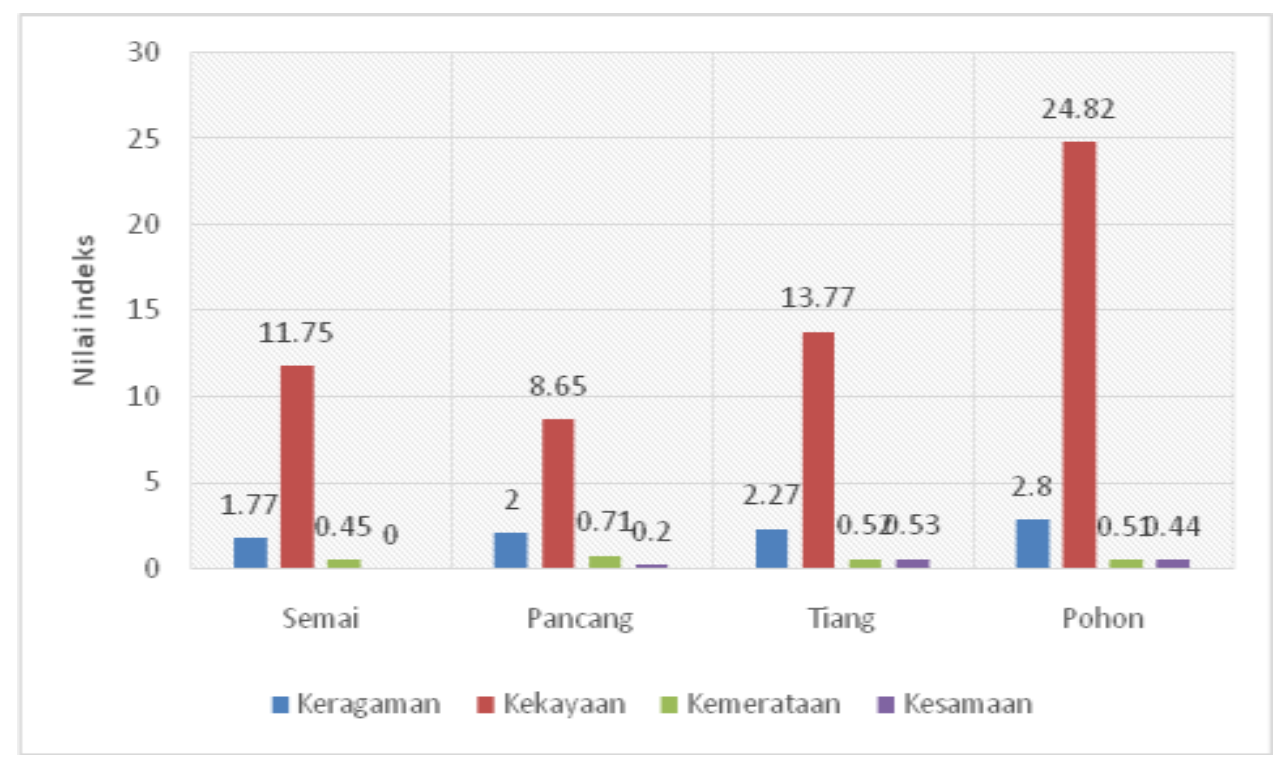

Gambar 6. NilaiIndeksKeragaman, Kekayaan, Kemerataan, dan Kesamaan Vegetasi 
Kondisi habitat ditinjau dari komponen abiotik, menunjukkan bahwa jenis tanah yang ada di plot permanen rafflesia Blok Krecek termasuk tanah latosol yang pada umumnya memiliki warna merah hingga gelap, teksturnya lempung dan memiliki horizon. Lapisan horizon yang dimiliki oleh tanah latosol cenderung tebal namun demikian batas horizon tanah latosol tidak terlihat begitu jelas. Kelembaban tanah cukup tinggi yaitu $86,67 \%$, hal ini diasumsikan dipengaruhi oleh curah hujan yang cukup tinggi pada Januari 2017.Adapun rata-rata penutupan seresahyaitu 7,92 cm, juga dapat mempengaruhi kelembaban tanah dengan cara menahan lapisan tanah untuk melakukan pengguapan, sehingga kelembaban tanah tinggi. Kelerengan $80 \%$, padalokasi penelitian menunjukkan bahwa memang plot permanen rafflesia memiliki lahan yang cukup curam, sedangkan untuk $\mathrm{pH}$ tanah dapat dikatakan netral karena dari keseluruhan atau rata-rata $\mathrm{pH}$ mendekati 7.Kawasan Taman Nasional Meru Betiri memiliki curah hujan tinggi yang ditandai dengan tampilan hijau muda atau sekitar 301 - 400 mm pada Januari 2017. Melihat dari prakiraan curah hujan bulanan tersebut dan apabila dijadikan prakiraan curah hujan tahunan maka menjadi 1806 - 2400 mm/tahun. Menurut Zuhud (1998) curah hujan rata-rata tahunan untuk spesies $R$. zollingeriana Kds. adalah 1867 - 2397 mm/tahun. Hal ini menjukkan bahwa Kawasan Taman Nasional Meru Betiri merupakan tempat tumbuh yang sesuai untuk rafflesia.

\section{Asosiasi Rafflesia zollingeriana Kds.}

Interaksi yang terjadi diantara jenis dipengaruhi oleh faktor kerapatan dan frekuensi yang tinggi, sehingga menghasilkan asosiasi yang positif (Deshmukh, 1992). Asosiasi negatif tidak menunjukkan adanya toleransi untuk hidup bersama pada area yang sama atau dapat dikatakan tidak ada hubungan timbal balik yang saling menguntungkan khususnya dalam pembagian ruang hidup (Muller,
1974). Kerapatan dan frekuensi yang cukup tinggi di dalam suatu populasi akan menimbulkan adanya tarik menarik antara jenis dalam rangka memanfaatkan lingkungan yang ada untuk menciptakan kondisi kondisi hidup yang stabil. Kondisi ini memberi pengertian bahwa interaksi yang terjadi secara alami, dapat bertahan untuk jangka waktu yang panjang selama komunitas tersebut berada dalam keadaan seimbang. Pernyataan ini sangat mendukung kondisi vegetasi di plot permanen rafflesia Blok Krecek, sebab berdasarkan data analisis vegetasi seperti kerapatan dan frekuensi, sangat menunjang untuk terjadinya interaksi positif antara spesies-spesies yang ada. Berdasarkan hasil analisis, bahwa asosiasi yang terjadi pada rafflesia dengan spesies lain di plot rafflesia Blok Krecek pada umumnya adalah positif. Tercatat ada 9 macam spesies yang memiliki asosiasi positif dengan rafflesia. Spesies yang berasosiasi positif dengan rafflesia tersebut antara lain sriwilkutil (Sterculia companulata Jw.); bindung (Tetramele smudiflora Gott.); berasan (Drypetesovalis L.); endokan (Xantho phylum vitellinum BI. Dietr.); jerukan (Polyal thiaruphii L.); talesan (Perseao doratis Kosterm.); apak (Ficus benjamina L.); bendo (Artocarpu selasticus Reinw. B1.); dan kecapi (Sondori cumkoetjapie Mal.). Hal ini dapat dikatakan bahwa plot permanen rafflesia Blok Krecek mempunyai kompleksitas ekologi yang tinggi dengan beberapa jenis yang berasosiasi positif dengan rafflesia. Asosiasi antar spesies ini juga dinyatakan dalam tingkat kekuatan asosiasi. Berdasarkan hasil uji indeks ochiai, dice dan jaccard antara rafflesia dengan spesies lain menunjukkan adanya variasi data, hal ini ditandai dengan derajat indeks yang berbeda-beda. Tercatat 2 spesies yaitu sriwil kutil (Sterculia campanulata Jw.) dan bindung (Tetrameles mudiflora Gott.) pada tingkat pertumbuhan pancang mendapatkan derajat indeks yang maksimal dengan nilai 1 . Hal ini dapat diasumskan dari 9 macam spesies yang memiliki asosiasi positif dengan rafflesia, hanya ada 2 spesies 
yang memiliki asosiasi positif maksimal yaitu sriwil kutil (Sterculia campanulata Jw.) dan bindung (Tetrameles mudiflora Gott.), selain spesies tersebut tetap memiliki asosiasi positif, akan tetapi asosiasinya tidak maksimal.

\section{Kesimpulan}

1) Tercatat sebanyak 4 individu Rafflesia zollingeriana Kds. dengan kondisiyakni3 individu knop segar dan 1 individu mati, yang hidup secara mengelompok pada plot 1 . Habitat biotik $R$. zollingeriana Kds. yaitutumbuh pada akar dan batang Tegtrastigmasp, dengan spesies dominansinya bendo (Artocarpus elasticus Reinw. B1.) dan jerukan (Polyalthiaruphii L.). Habitat abiotiknya dicirikan pada ketinggian 1170 meter di atas permukaan laut, kelerengan curam, dan tumbuh pada iklim C.

2) Asosisi antara $R$. zollingeriana Kds. dengan vegetasi lain pada umumnya memiliki asosiasi positif, namun dari keseluruhan spesies yang telah ditemukan, asosiasi maksimum terjadi antara $R$. zollingeriana Kds. dengan sriwil kutil (Sterculia campanulata Jw.) bindung (Tetrameles mudiflora Gott.).

\section{Saran}

Perlu dilakukan pemetaan persebaran Rafflesia zollingeriana Kds. terbaru di Taman Nasional Meru Betiri beserta inventarisasi inang tetrastigma secara teratur, untuk menentukan waktu mekar bunga $R$. zollingeriana Kds., sehingga dapat memberikan nilai tambah dalam aspek konservasi.

\section{DaftarPustaka}

Ali, M. 2014. Karakteristik Habitat Raffleisa (Rafflesia patma Blume.) di Cagar Alam Bojonglarang Jayanti Cianjur Jawa Barat. Bogor: Institut Pertanian Bogor.

Bismark, M. 2011. Prosedur Perasi Standar (SOP) Untuk Survey Keragaman Jenis Pada Kawasan Konservasi. Kementerian Kehutanandan ITTO. Bogor.

Lestari, D. 2013. Konservasi Rafflesia zollingeriana. Kds di Taman Nasional Meru Betiri. Bogor: Institut Pertanian Bogor.

Ludwig, R. 1988. Statistical Ecology. Canada: A Primer on Methods and Computing.

Muller. 1974. Aims and Method of Vegetation Ecology. New York: Wiley International Edition.

Prasetyo, F. 2016. Petunjuk Prektek Pengelolaan Hutan Tanaman. Yogyakarta: Fakultas Kuhutanan Universitas Gajah Mada.

Setiadi. 1984. Ekologi Tropika. Bandung: Institut Teknologi Bandung.

Sugianto, A. 1994. Ekologi Kuantitatif. Surabaya: Usaha Nasional.

Zuhud. 1989. Ecologic Study of Rafflesia zollingeriana Kds in Meru Betiri National Park. Bogor: Bogor Agricultural University.

Zuhud. 1998. Rafflesia Indonesia Keanekaragaman, Ekologi dan Pelestariannya. Bogor: Yayasan Pembina Swaka Alam dan Margasatwa Indonesia. 